Kanefumi Kitaharaa
Satoshi Fukunaga $^{\text {a }}$
Kenji Katayama $^{\mathbf{b}}$
Yasuhiro Takahata $^{\text {b }}$
Yoshinori Nakazawa $^{\text {b }}$
Masaru Yoshinaga $^{\text {b }}$
Toshihiko Suganuma $^{\text {a }}$
a Department of Biochemical
Science and Technology,
Faculty of Agriculture,
Kagoshima University,
Kagoshima, Japan
b Department of Upland Farming
Research, National Agricultural
Research Center for Kyushu
Okinawa Region, Miyakonojo,
Miyazaki, Japan

\section{Physicochemical Properties of Sweetpotato Starches with Different Gelatinization Temperatures}

\begin{abstract}
Physicochemical properties of five sweetpotato starches differing in gelatinization temperature were examined. The gelatinization temperature of Koganesengan starch, an ordinary cultivar of sweetpotato in Japan, was $73.6^{\circ} \mathrm{C}$, whereas those of the other starches were measured to be $71.6^{\circ} \mathrm{C}$ for Kyukei $96162-1,65.8^{\circ} \mathrm{C}$ for Kyushu No.127, $63.9^{\circ} \mathrm{C}$ for Kyukei 240 , and $54.9^{\circ} \mathrm{C}$ for Quick Sweet. Some relationships of the primary structural properties with the gelatinization temperature have been found. As the gelatinization temperature decreased: i) the content of phosphate groups attached to the glucosyl residues decreased, ii) the amylose content, which was determined as difference in long chains of debranched original starch and of its amylopectin, decreased, iii) the proportion of unit chains with DP $>100$ in the amylopectin fraction increased, iv) the proportion of unit chains with DP 6 to 10 in the amylopectin fraction increased, whereas that of unit chains with DP 12 to 24 decreased, v) the B-type crystallinity of the starch granules was enhanced, and vi) the proportion of longer chains constituting each Nägeli amylodextrin increased. Moreover, it was found that thin pastes of the low temperaturegelatinizing starches retrograded slower during cold storage than the ordinary starch. Among the starches, Quick Sweet starch granules, having the lowest gelatinization temperature, were digested rapidly by pancreatin.
\end{abstract}

Keywords: Sweetpotato starch; Gelatinization temperature, Chain-length distribution

\section{Introduction}

Starches from different botanical sources, from different cultivars, and from the same cultivars grown under different conditions are characterized by differing physicochemical properties. Among these properties, gelatinization temperature is especially important, because the utilization of starches depends almost totally on gelatinization. Recently, new sweetpotatoes containing a starch gelatinizing at low temperature, i.e. Kyushu No. 127 line [1] and the Quick Sweet cultivar [2], have been found and developed by the National Agricultural Research Center for Kyushu Okinawa Region and the National Institute of Crop Science in Japan, respectively. The gelatinization temperature of the two starches was 10$20^{\circ} \mathrm{C}$ lower than that of ordinary sweetpotato starch. This low gelatinization temperature would be an advantage for their economical industrial use, because less heat energy would be needed to make starch pastes compared to those made of ordinary sweetpotato starches.

In some recent reports concerning the relationships between gelatinization temperature and molecular structures of sweetpotato starches no correlation was found between

Correspondence: Kanefumi Kitahara, Department of Biochemical Science and Technology, Faculty of Agriculture, Kagoshima University, 1-21-24, Korimoto, Kagoshima 890-0065, Japan. Phone: +81-99-285-8638, Fax: +81-99-285-8639, e-mail: kitahara@chem.agri.kagoshima-u.ac.jp.

(C) 2005 WILEY-VCH Verlag GmbH \& Co. KGaA, Weinheim amylose content and gelatinization temperature [3, 4]. It is of interest to note that, with respect to the chain-length distribution of amylopectin, a maize line having the lowest amount of unit chains with DP 6-11 showed the highest gelatinization temperature [5]. Noda et al. [4] reported that the gelatinization temperature of sweetpotato starches was negatively correlated with the amount of unit chains with DP 6-10 in their amylopectins. Interestingly, it was found that both low temperature-gelatinizing starches from the new sweetpotatoes mentioned above had also a high proportion of unit chains with DP 6-11 [1, 2].

In this paper, in order to further investigate relations between gelatinization temperature and starch properties as well as the unit chains in the amylopectin, five sweetpotato starches differing in gelatinization temperature were selected as samples, and their physicochemical properties were examined in detail.

\section{Materials and Methods}

\subsection{Starches and reagents}

Four kinds of new sweetpotatoes, Kyukei 96162-1 (K96162-1), Kyushu No. 127 (K127), Kyukei 240 (K240), and Quick Sweet (QS), containing starches which gelatinize at lower temperature than those of ordinary cultivars, and Koganesengan (KG), an ordinary sweetpotato cultivar in Japan, were cropped on an experimental field of 
Kagoshima University in 2002. The tuberous roots were harvested after cultivation for five months. The peel and cambium tissues were removed from the tuberous roots, then the inner tissue was mashed with cold deionized water and passed through a Miracloth (Calbiochem, Merck Ltd., Japan) and a 200-mesh screen. The starch was repeatedly suspended and settled in fresh deionized water for purification and then dried. The starch was dissolved in dimethyl sulfoxide for defatting and then precipitated with ethanol [6]. Amylopectin was fractionated from the defatted starch by the method of Takeda et al. [6]. The amylopectin sample was free of amylose, as shown by Takeda et al. [7]. Commercial starches from normal maize and potato were obtained from Nihon Starch Co., Ltd., Kagoshima, Japan. Nägeli amylodextrins were prepared by leaching starch granules $(20 \mathrm{~g})$ with $15 \%(\mathrm{w} / \mathrm{w})$ sulfuric acid $(200 \mathrm{~mL})$ at $37^{\circ} \mathrm{C}$ with shaking by hand once a day for $7-25$ days until $40 \%$ solubilization of the respective starches was obtained.

All reagents and solvents, unless otherwise specified, were obtained from Wako Pure Chemical Industries, Osaka, Japan, and were of analytical grade.

\subsection{Pasting and general properties of starches}

Pasting properties of the starches were determined in a Brabender Viscograph PT-100 (Brabender OHG, Duisburg, Germany) using a $6 \%(w / w)$ aqueous starch suspension, except for potato starch (4\%) [8]. Defatted starch (50 mg, d.w.), obtained as described above, was dissolved by adding dimethyl sulfoxide $(1 \mathrm{~mL})$ and heating at $70^{\circ} \mathrm{C}$ for $3 \mathrm{~h}$, and then the solution was filled up to $100 \mathrm{~mL}$ with distilled water and allowed to stand for $1 \mathrm{~h}$. To the defatted starch solution $(8 \mathrm{~mL}) 4 \mathrm{~mL}$ of $0.2 \% \mathrm{I}_{2} / 2 \% \mathrm{KI}$ solution was added and filled up to $50 \mathrm{~mL}$. After standing for $1 \mathrm{~h}$ at $25^{\circ} \mathrm{C}$, the absorbance of the solution was measured at $680 \mathrm{~nm}$ (spectrophotometer U-3310, Hitachi, Tokyo, Japan). The apparent amylose content was calculated from the absorbance at $680 \mathrm{~nm}$ (blue value, B.V.) of the defatted starch on the basis of the values of amylose (B.V. $=1.47$ ) and amylopectin (B.V. $=0.21$ ) from sweetpotato starch (cv. Koganesengan) [9]. Crude protein content was determined by the Kjeldahl method [10] and represented as nitrogen $\times 6.25$. Phosphate groups bound to the glucosyl residues were converted into inorganic phosphate by ashing of the defatted starch (50 mg, d.w.) with $60 \%$ perchloric acid $(1 \mathrm{~mL})$ and with the aid of four drops of nitric acid. The inorganic phosphate was determined by the Fiske-Subbarow method [11]. The X-ray diffractogram was obtained using a Rigaku RU-200B X-ray diffractometer (Rigaku, Tokyo, Japan) [8].

\subsection{Chain-length distribution of debranched starches and amylopectins}

Defatted starch or amylopectin $(25 \mathrm{mg})$ was gelatinized in $1 \mathrm{M}$ sodium hydroxide $(250 \mu \mathrm{L})$ over night at $5^{\circ} \mathrm{C}$. Distilled water $(3 \mathrm{~mL})$ was added to the gelatinized sample, and the solution was neutralized with $1 \mathrm{M}$ acetic acid $(750 \mu \mathrm{L}$, $\mathrm{pH} 4-5)$. After adding $2 \%$ sodium azide $(50 \mu \mathrm{L})$, the solution was incubated with $2.5 \mathrm{U}$ of Pseudomonas isoamylase (Nacalai Tesque Inc., Kyoto, Japan) at $45^{\circ} \mathrm{C}$ for $6 \mathrm{~h}$ (final volume $5 \mathrm{~mL}$ ). One unit of isoamylase causes the formation of $1 \mu \mathrm{mol}$ of reducing sugar in $1 \mathrm{~min}$. Under these conditions, the samples were debranched completely. The chain-length distribution of the debranched sample was determined by high-performance gel-permeation chromatography (CCPM-II pump, RI-8022 detector, Tosoh, Tokyo, Japan) using two linked columns of Superose $6(1 \times 30 \mathrm{~cm}$, Amersham Bioscience, Tokyo, Japan) and Sephadex G25SF $(1 \times 30 \mathrm{~cm}$, Amersham Bioscience) [12]. The column system was calibrated using synthesized linear amyloses $(D P=1953,722,438,215$, 63, Ajinoki, Aichi, Japan), Amylose EX-1 (DP = 17, Hayashibara Biochem. Lab. Inc., Okayama, Japan) and maltoheptaose (Hayashibara Biochem. Lab. Inc.). The debranched amylopectin was also examined by high-performance anion-exchange chromatography (HPAECPAD) using a CarboPac PA-1 column with a guard column (Nippon Dionex K.K., Osaka, Japan) [13]. In the case of Nägeli amylodextrin, the sample was debranched successively by isoamylase and then pullulanase (Hayashibara Biochem. Lab. Inc.) according to the method previously reported [14]. These chromatographic experiments were performed in duplicate with good agreement between the replicate results.

\subsection{Retrogradation of starch pastes}

Starch suspended in water $(2 \%, \mathrm{w} / \mathrm{v}, 7 \mathrm{~mL})$ was gelatinized in a boiling water bath for $20 \mathrm{~min}$ and thereafter stored at $4^{\circ} \mathrm{C}$ for 7 days. Turbidity development of the starch paste was measured using a Klett-Summerson photoelectric colorimeter with a filter of number 66 (red filter).

\subsection{Digestibility of starch granules by pancreatin}

Starch granules (100 mg, d.w.) were digested by $1 \%$ pancreatin ( $5 \mathrm{~mL}$, from hog pancreas) containing $20 \mathrm{mM}$ sodium phosphate buffer ( $\mathrm{pH}$ 6.9), $7 \mathrm{mM}$ sodium chloride, $1 \mathrm{mM}$ calcium chloride, and $0.02 \%$ sodium azide. The reaction mixture was kept at $37^{\circ} \mathrm{C}$ for various periods with gentle rotating. After centrifugation of the reaction mixture, total carbohydrate in the supernatant was measured by the phenol-sulfuric acid method [15]. 


\section{Results}

\subsection{Structural properties of low temperature- gelatinizing starches}

Tab. 1 shows the pasting properties of five kinds of sweetpotato starches on a Viscograph, as well as those of commercial maize and potato starches. The gelatinization temperature of $\mathrm{KG}$ starch, an ordinary cultivar of sweetpotato in Japan, was $73.6^{\circ} \mathrm{C}$, whereas those of other starches were measured to be $71.6^{\circ} \mathrm{C}$ for K96162-1, $65.8^{\circ} \mathrm{C}$ for $\mathrm{K} 127,63.9^{\circ} \mathrm{C}$ for $\mathrm{K} 240$, and $54.9^{\circ} \mathrm{C}$ for $\mathrm{QS}$. The gelatinization temperatures of K127, K240 and QS starches were comparable to or lower than that of potato starch. The starches from K127, K240 and QS showed smaller breakdown and larger setback compared to the ordinary sweetpotato starch from KG.

Tab. 1 also shows the general properties of the starches. The apparent amylose contents of the sweetpotato starches ranged from $13.6 \%$ to $16.2 \%$ and were similar to starches from 16 kinds of sweetpotato cultivars [3]. The amylose content of QS starch was slightly lower than that obtained in the previous report (QS is named as Kanto 116 in that report) [2], which may be due to differences in culture conditions and analytical standards of amylose and amylopectin. It was found that the content of attached phosphate groups decreased in the order of decreasing gelatinization temperature. The phosphate content of QS starch was $0.91 \mu \mathrm{mol} / \mathrm{g}$ starch, which was comparable to that of the maize starch. In general, X-ray diffractograms of maize and potato starches are distinguishable as A type and B type, respectively, and that of sweetpotato starch is classified as $C$ type, which is a mixture of $A$ and $B$ type crystallites [16]. As shown in Fig. 1, the B-type crystallinity of the starch granules was enhanced as the gelatinization temperature decreased, although all sweetpotatoes were grown in the same field. Interestingly, QS starch practically showed a B-type diffraction pattern.

Fig. 2 shows chain-length distributions of the debranched starches and amylopectins. The distributions of the debranched starches were divided into three fractions, Fr.1, Fr.2 and Fr.3, as shown in Fig. 2, which correspond roughly to an amylose fraction and two unit-chain fractions from amylopectin, respectively [17]. Tab. 2 summarizes the proportions of each fraction and the ratio of Fr.3 to Fr.2 as an index of amylopectin structure. The

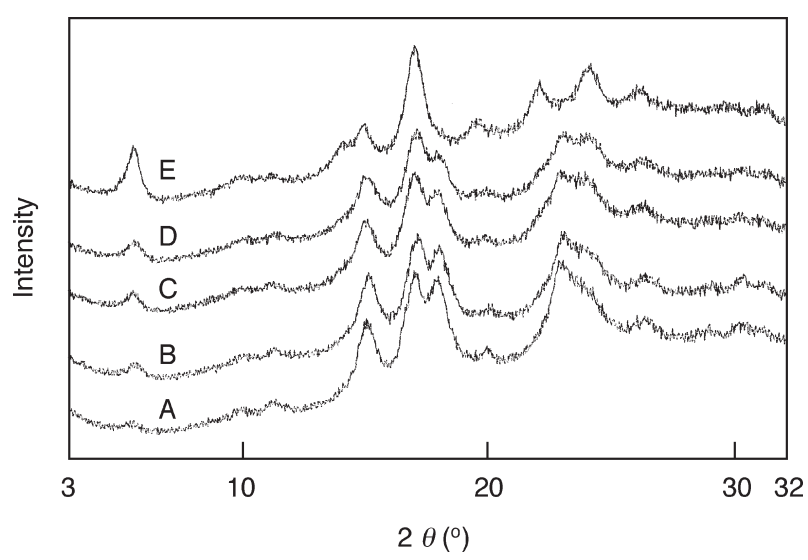

Fig. 1. X-ray diffractograms of sweetpotato starches. A: Koganesengan, B: Kyukei 96162-1, C: Kyushu No.127, D: Kyukei 240, and E: Quick Sweet.

Tab. 1. Pasting and general properties of starches.

\begin{tabular}{|c|c|c|c|c|c|c|c|}
\hline & \multicolumn{4}{|c|}{ Brabender viscogram $^{a}$} & \multirow{2}{*}{$\begin{array}{l}\text { Apparent } \\
\text { amylose } \\
\text { content }^{\mathrm{b}} \\
{[\%]}\end{array}$} & \multirow{2}{*}{$\begin{array}{l}\text { Crude } \\
\text { protein }^{c} \\
{[\%]}\end{array}$} & \multirow{2}{*}{$\begin{array}{l}\text { Phos- } \\
\text { phate }^{d} \\
{[\mu \mathrm{mol} / \mathrm{g}} \\
\text { starch] }\end{array}$} \\
\hline & $\begin{array}{l}\text { Gelatinization } \\
\text { temperature } \\
{\left[{ }^{\circ} \mathrm{C}\right]}\end{array}$ & $\begin{array}{l}\text { Peak } \\
\text { viscosity } \\
{[\mathrm{BU}]}\end{array}$ & $\begin{array}{l}\text { Breakdown } \\
{[\mathrm{BU}]}\end{array}$ & $\begin{array}{l}\text { Setback } \\
{[\mathrm{BU}]}\end{array}$ & & & \\
\hline Koganesengan & 73.6 & 887 & 327 & 275 & 15.9 & 0.03 & 5.57 \\
\hline Kyukei 96162-1 & 71.6 & 887 & 417 & 293 & 13.6 & 0.03 & 3.42 \\
\hline Kyushu No.127 & 65.8 & 666 & 37 & 396 & 16.2 & 0.01 & 2.07 \\
\hline Kyukei 240 & 63.9 & 707 & 52 & 385 & 15.9 & 0.03 & 1.99 \\
\hline Quick Sweet & 54.9 & 765 & 54 & 364 & 14.1 & 0.02 & 0.91 \\
\hline Maize & 83.0 & 250 & 55 & 205 & 21.2 & 0.23 & 0.79 \\
\hline Potato & 66.5 & 650 & 305 & 90 & 18.8 & 0.01 & 19.9 \\
\hline
\end{tabular}

a: Measured at $6 \%(\mathrm{w} / \mathrm{w})$ starch concentration, except for potato starch $(4 \%)$, by a Brabender Viscograph PT-100.

b: Calculated from the respective blue values of defatted starches on the basis of those of amylose (1.47) and amylopectin (0.21) from Koganesengan starch.

c: Determined by the Kjeldahl method. Crude protein is represented as $\mathrm{N} \times 6.25$.

$\mathrm{d}$ : Determined by the Fiske-Subbarow method after $\mathrm{HClO}_{4}$ incineration of defatted starches. 

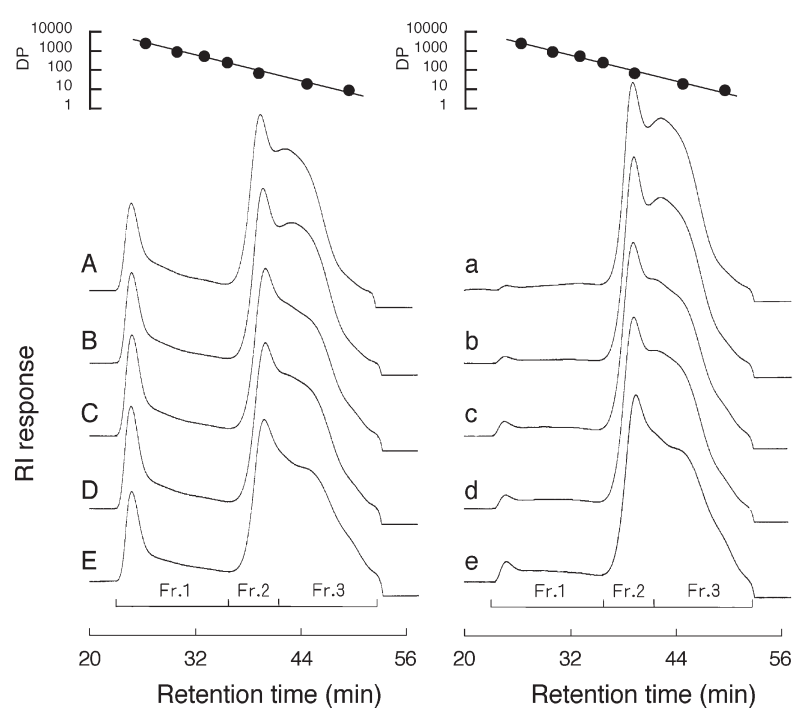

Fig. 2. Chain-length distribution of debranched starches and amylopectins. Capital letters indicate the debranched whole starches, and small letters indicate the debranched amylopectins. A and a: Koganesengan, B and b: Kyukei 96162-1, C and c: Kyushu No.127, D and d: Kyukei 240, and E and e: Quick Sweet.

proportions of Fr.1 for the debranched starches ranged from $18.0 \%$ to $20.4 \%$, which correspond to those of starches from 16 kinds of sweetpotato cultivars [3]. It was reported that long chains having $D P>100$ were found in amylopectins e.g. from Indica rice [7], wheat [18] and maize [19]. The chain-length distributions of the sweetpotato amylopectins showed that all amylopectins had long chains (DP>100) eluting at Fr.1, and the amount of the long chains increased with decrease in the gelatinization temperature. Therefore, the amylose content of the starches was evaluated as the difference in the respective amounts of Fr.1 in starch and in amylopectin. The differential amount of Fr. $1(\Delta \mathrm{Fr} .1)$ is considered to be a more accurate value of the amylose content than the apparent amylose content and the proportion of Fr.1 for debranched starch, because of the existence of the long chains in amylopectin. As shown in Tab. 2, it was found that $\Delta \mathrm{Fr} .1$ of the starches decreased as the gelatinization temperature decreased. On the other hand, although the ratios of Fr.3 to Fr.2 were nearly identical among both starches and amylopectins, the elution profiles at Fr.3 of $\mathrm{K} 127, \mathrm{~K} 240$, and QS were distinctly different from that of $K G$ starch. Furthermore, the distribution of unit chains between DP 6-40 of their amylopectins was analyzed by HPAEC-PAD. The difference in distribution of each amylopectin was estimated by subtracting the relative peak area (\%) of KG amylopectin from those of the other amylopectins (Fig. 3). The amylopectins of the low temperature gelatinizing starches had a higher proportion of unit chains with DP 6-10 and a lower proportion of unit chains

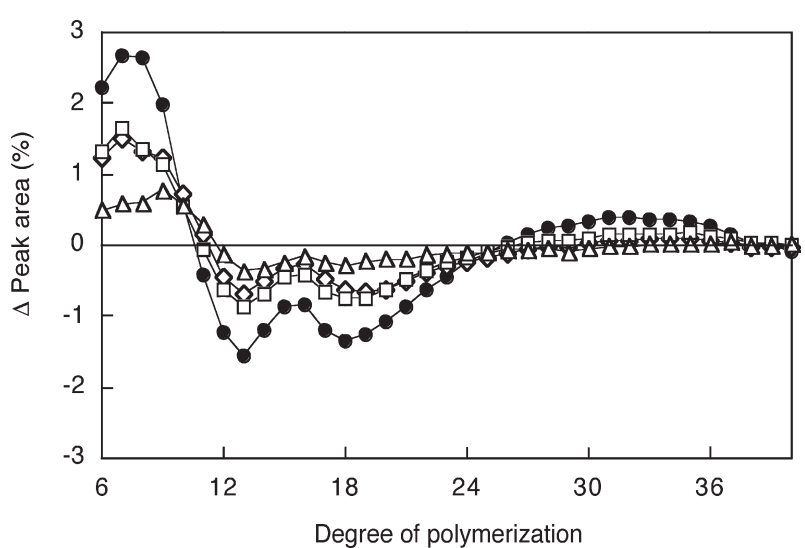

Fig. 3. Difference in short chain distributions of starches compared to Koganesengan starch. $\Delta$ : Kyukei 96162-1, $\square$ : Kyushu No.127, $\diamond:$ Kyukei 240, and O: Quick Sweet.

Tab. 2. Fractions of debranched starches and amylopectins of sweetpotatoes.

\begin{tabular}{|c|c|c|c|c|c|}
\hline & $\begin{array}{l}\text { Fr. } 1^{\mathrm{a}} \\
{[\%]}\end{array}$ & $\begin{array}{l}\text { Fr.2 }{ }^{\mathrm{a}} \\
{[\%]}\end{array}$ & $\begin{array}{l}\text { Fr.3 }{ }^{a} \\
{[\%]}\end{array}$ & $\begin{array}{l}\text { Fr.3/ } \\
\text { Fr. } 2^{\mathrm{b}}\end{array}$ & $\begin{array}{l}\Delta \mathrm{Fr} .1^{\mathrm{c}} \\
{[\%]}\end{array}$ \\
\hline \multicolumn{6}{|l|}{ Starches } \\
\hline Koganesengan & 19.4 & 32.8 & 47.8 & 1.5 & 16.1 \\
\hline Kyukei 96162-1 & 18.0 & 32.2 & 49.8 & 1.5 & 14.8 \\
\hline Kyushu No.127 & 20.4 & 30.9 & 48.6 & 1.6 & 13.9 \\
\hline Kyukei 240 & 20.3 & 29.7 & 50.0 & 1.7 & 14.1 \\
\hline Quick Sweet & 19.3 & 30.2 & 50.5 & 1.7 & 11.5 \\
\hline \multicolumn{6}{|l|}{ Amylopectins } \\
\hline Koganesengan & 3.3 & 35.6 & 61.1 & 1.7 & - \\
\hline Kyukei 96162-1 & 3.2 & 35.6 & 61.2 & 1.7 & - \\
\hline Kyushu No.127 & 6.5 & 35.5 & 58.0 & 1.6 & - \\
\hline Kyukei 240 & 6.2 & 36.6 & 57.2 & 1.6 & - \\
\hline Quick Sweet & 7.8 & 35.4 & 56.8 & 1.6 & - \\
\hline
\end{tabular}

a: Fractionation of each fraction is shown in Fig. 2.

b: Ratio of Fr.3 to Fr.2.

c: Difference of the starch and amylopectin in Fr.1.

with DP12-24 than KG amylopectin. The results from K127 and QS starches agreed with the previous reports $[1,2]$.

Nägeli amylodextrin is an acid-resistant residue of the starch granule, which is considered to be the highly crystalline part made up of double helices after eroding away the amorphous parts $[20,21]$. The time for $40 \%$ degradation of the starch granules by $15 \%$ sulfuric acid to be achieved was 7 days for QS, 13 days for K127 and K240, 18 days for K96162-1, and 25 days for KS. The result indicates that the starches with a lower gelatinization temperature are more susceptible to acid treatment. Fig. 4 shows gel-permeation chromatograms of Nägeli amylodextrins and those after debranching by isoamylase and 


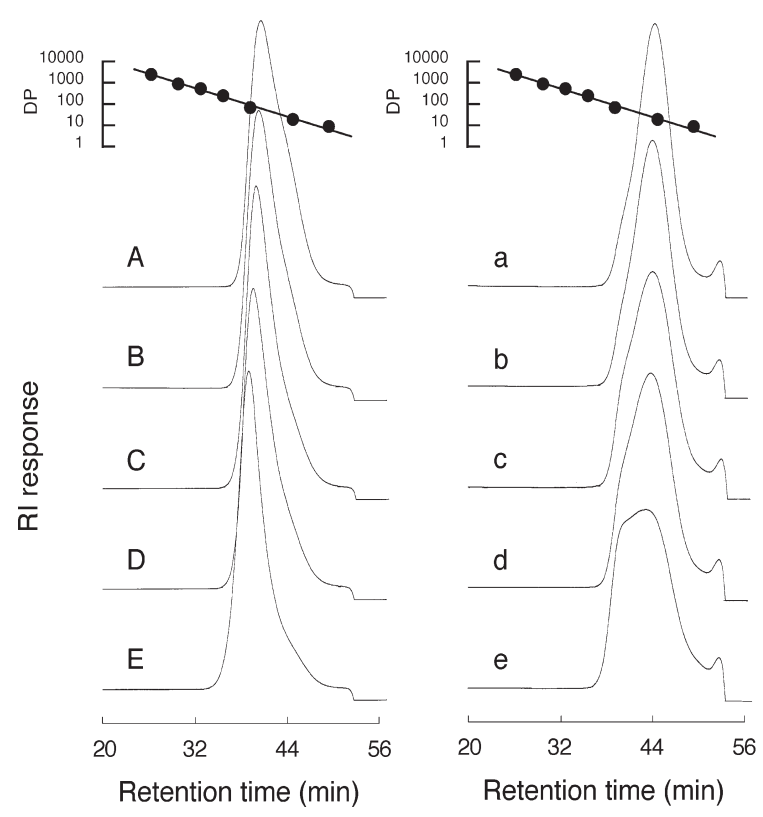

Fig. 4. Gel-permeation chromatograms of Nägeli amylodextrins and their debranched dextrins. Capital letters indicate the Nägeli amylodextrins, and small letters indicate their debranched dextrins. A and a: Koganesengan, B and b: Kyukei 96162-1, C and c: Kyushu No.127, D and d: Kyukei 240, and E and e: Quick Sweet.

pullulanase. The completion of the debranching treatment was confirmed by the constant reducing power during reaction. Since glycosyl branches resulting from heterogeneous acid hydrolysis cannot be hydrolyzed by both isoamylase and pullulanase [22], a small amount of the glucosyl stubs would remain in the debranched samples [21]. The elution profiles of Nägeli amylodextrins showed nearly a single peak on this column, and the peak DP was estimated to be 53 for KG, 59 for K96162-1, 67 for K127, 67 for K240, and 77 for QS on the basis of calibration standards. After debranching the Nägeli amylodextrins, the single peaks of the Nägeli amylodextrins were shifted to the lower molecular weight side, and a shoulder was observed on the high molecular weight side. The magnitude of the shoulder increased with decreasing gelatinization temperature, indicating that the lower the gelatinization temperature of the starches, the more abundant the longer unit chains constituting their Nägeli amylodextrins. This result was also confirmed using HPAEC-PAD (data not shown).

\subsection{Other properties of low temperature- gelatinizing starches}

Fig. 5 shows the turbidity developments of $2 \%$ starch pastes during storage at $4^{\circ} \mathrm{C}$ for 7 days as an index of starch retrogradation. The pastes of the sweetpotato

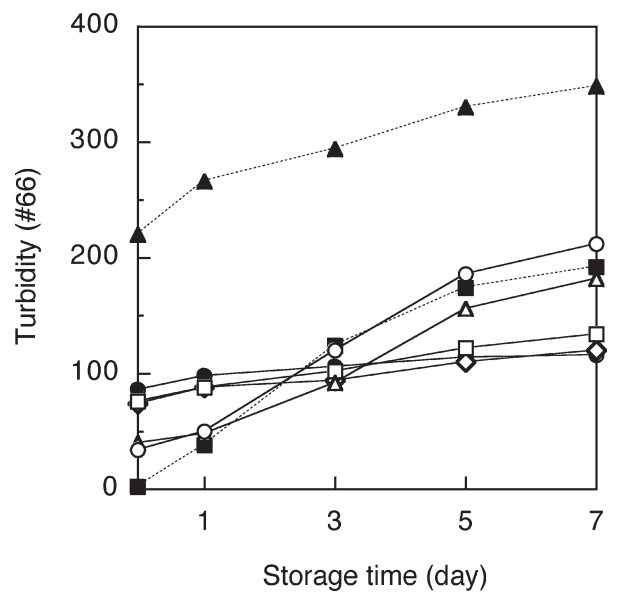

Fig. 5. Turbidity development of $2 \%$ starch pastes during storage at $4^{\circ} \mathrm{C}$. The turbidity was measured by a Klett colorimeter with a \#66 filter. $\bigcirc$ : Koganesengan, $\triangle$ : Kyukei 96162-1, $\square$ : Kyushu No.127, $\diamond$ : Kyukei 240, ○: Quick Sweet, $\boldsymbol{\Delta}$ with dotted line: Maize, and $\boldsymbol{\square}$ with dotted line: Potato.

starches showed intermediate turbidity between those of potato and maize starch pastes at the start of storage. During storage of the starch pastes, the turbidities of the maize, potato, KG and K96162-1 starches developed rapidly. On the other hand, little change was observed in the turbidities of the K127, K240 and QS starch pastes during cold storage, suggesting that such starches have a favorable anti-retrogradation characteristic.

Fig. 6 shows the digestibilities of the starch granules by pancreatin, which consists of digestive enzymes including $\alpha$-amylase from hog pancreas. The sweetpotato starch from KG showed intermediate digestibility between those of potato and maize starches. It was found



Fig. 6. Digestibility of starch granules by pancreatin. $\bigcirc$ : Koganesengan, $\triangle$ : Kyukei 96162-1, $\square$ : Kyushu No.127, $\diamond$ : Kyukei 240, ๑: Quick Sweet, $\Delta$ with dotted line: Maize, and $\mathbf{W}$ with dotted line: Potato. 
that the digestibilities of the sweetpotato starches increased as gelatinization temperatures decreased. The QS starch, especially, showed the best digestibility among the starches used here. Although it was reported that the digestibility of sweetpotato starches was dependent on their granular size [23], the high digestibility of the low temperature-gelatinizing sweetpotato starches was not dependent on the granular size (data not shown).

\section{Discussion}

In this paper, the physicochemical properties of five kinds of sweetpotato starches differing in gelatinization temperature have been revealed. Among these starches, K127 starch and K240 starch, showing similar gelatinization temperatures, were similar to each other with respect to all physicochemical properties.

It has been reported that the gelatinization temperature of sweetpotato starches was closely related to the proportion of unit chains with DP 6-10 in their amylopectin [4]. Among the five sweetpotato starches used in this study, a negative correlation (correlation coefficient: $r=-0984$, $p<0.01$ ) was confirmed between the proportion of unit chains with DP 6-10 and the gelatinization temperature. This would be due to the difficulty of such short chains to form a double-helical order, resulting in less crystalline perfection [24, 25]. Additionally, it was found that thin pastes of the low temperature-gelatinizing starches having a high proportion of unit chains with DP 6-10 retrograded slower than ordinary sweetpotato starch during cold storage. This result also agreed with previous reports that the short chains ( $<$ DP11) inhibited retrogradation of starch [26-28]. Furthermore, cracking of QS starch granules was observed around their granule center, which may be caused by changes in the crystallinity of the granules [2]. These distinctive features would be the reason for the high susceptibility of QS starch granules to the action of pancreatin.

X-ray diffraction analysis of the starches revealed that there is an inverse dependency between the increase in B-type crystallinity of the starch granules and the gelatinization temperature of the starches. It was demonstrated that the Nägeli amylodextrins of the low temperaturegelatinizing starches, which are considered to be a crystalline part of the starch granules, contained a higher amount of longer chains compared to ordinary sweetpotato starch. This result suggests that the longer chains participate partly in the crystalline structure in the case of the low temperature-gelatinizing starches, which could explain that the low temperature-gelatinizing starches show a B-type X-ray diffraction pattern, because the Btype structure is generally favored by longer chain length in chain crystallization [24, 25, 29]. It is likely that short unit chains such as DP 6-8 are located outside the crystallites [30].

Other statistical correlations were also found among the properties of the sweetpotato starches differing in gelatinization temperature. As the gelatinization temperature of the starches decreased: firstly, the phosphate content decreased $(r=0.898, p<0.05)$; secondly, the amylose content $(\Delta \mathrm{Fr} .1)$ decreased $(r=0.971, p<0.01)$; and finally, the proportion of long chains with more than DP 100 (Fr.1 of amylopectin) in their amylopectins increased $(r=-0.940, p<0.05)$. This relation of the phosphate content to the gelatinization temperature was also found for nine kinds of potato starch [31]. On the other hand, no correlation has been found so far between the apparent amylose content of sweetpotato starches and the gelatinization temperature [3, 4]. At present, it is not clear, which factors and to what extent these factors are related to the low temperature-gelatinizing property of the starches, other than there is an abundance of unit chains with DP 6-10 in their amylopectins.

\section{Conclusion}

The physicochemical properties of new sweetpotato starches are described. With respect to the utilization of starches, slow retrogradation and good enzyme digestibility are attractive properties as well as low-temperature gelatinizing. Among the low temperature-gelatinizing starches, Quick Sweet starch has the lowest gelatinization temperature, $54.9^{\circ} \mathrm{C}$, which is about $20^{\circ} \mathrm{C}$ lower than that of ordinary sweetpotato starch. This would be a great advantage for industrial use because of saving heat energy for starch gelatinization. In addition, the slow retrogradation of the starch would enable a prolonged shelf life of various starchy foods, and the good enzyme digestibility of the starch might provide advantage for starch saccharification processes. We expect that low temperaturegelatinizing starches will create new applications for starch and contribute to the promotion of sweetpotato utilization. We are also interested in individual relations among the structural properties of the low temperature-gelatinizing starches in terms of the biosynthesis of starch granules. The relations between structural properties and starch biosynthetic enzymes still remain to be resolved.

\section{Acknowledgement}

This study was supported by Special Coordination Funds for Development of New Technology for Treatment and Local Recycling of Biomass from the Ministry of Agriculture, Forestry and Fisheries of Japan. 


\section{References}

[1] K. Kitahara, J. Ueno, T. Suganuma, K. Ishiguro, O. Yamakawa: Physicochemical properties of root starches from new types of sweetpotato. J. Appl. Glycosci. 1999, 46, 391-397.

[2] K. Katayama, K. Komae, K. Kohyama, T. Kato, S. Tamiya, K. Komaki: New sweet potato line having low gelatinization temperature and altered starch structure. Starch/Stärke 2002, 54, 51-57.

[3] K. Kitahara, Y. Ooi, S. Mizukami, T. Suganuma, T. Nagahama: Physicochemical properties of starches from sweetpotato cultivars. J. Appl. Glycosci. 1996, 43, 59-66.

[4] T. Noda, Y. Takahata, T. Sato, I. Suda, T. Morishita, K. Ishiguro, O. Yamakawa: Relationships between chain length distribution of amylopectin and gelatinization properties within the same botanical origin for sweet potato and buckwheat. Carbohydr. Polym. 1998, 37, 153-158.

[5] Y. C. Shi, P. A. Seib: Fine structure of maize starches from four wx- containing genotypes of the W64A inbred line in relation to gelatinization and retrogradation. Carbohydr. Polym. 1995, 26, 141-147.

[6] Y. Takeda, S. Hizukuri, B. O. Juliano: Purification and structure of amylose from rice starch. Carbohydr. Res. 1986, 148, 299-308.

[7] Y. Takeda, S. Hizukuri, B. O. Juliano: Structures of rice amylopectins with low and high affinities for iodine. Carbohydr. Res. 1987, 168, 79-88.

[8] K. Kitahara, T. Suganuma, S. Fujimoto, T. Nagahama: Characteristics of introduction of fatty acids into Gajutsu (Curcuma zedoaria Roscoe) and Teppo-yuri (Lilium longiflorum Thunb.) starches. Starch/Stärke 1993, 45, 30-34.

[9] C. Takeda, Y. Takeda, S. Hizukuri: Physicochemical properties of lily starch. Cereal Chem. 1983, 60, 212-216.

[10] AOAC International: Official Methods of Analysis of AOAC International, 16th Edition, AOAC Official Method 984.13, Gaithersburg, MD, USA, 1999.

[11] C. H. Fiske, Y. Subbarow: The colorimetric determination of phosphorus. J. Biol. Chem. 1925, 66, 375-400.

[12] K. Kitahara, T. Suganuma, T. Nagahama: Bound free fatty acids in glucoamylase-digested starches of corn and sweetpotato. Cereal Chem. 1994, 71, 439-443.

[13] K. Kitahara, K. Imamura, Y. Omae, T. Suganuma: Characterization of molecular structure of starch granules in suspension-cultured cells from Ipomoea cordatotriloba Denn. Biosci. Biotechnol. Biochem. 1998, 62, 1962-1967.

[14] K. Kitahara, E. Eitoku, T. Suganuma, T. Nagahama: Some properties of branched and linear dextrins from Nägeli amylodextrin. Carbohydr. Polym. 1997, 33, 187-194.

[15] M. Dubois, K. A. Gilles, J. K. Hamilton, P. A. Rebers, F. Smith: Colorimetric method for detemination of sugars and related substances. Anal. Chem. 1956, 28, 350-356.

[16] A. Imberty, A. Buléon, V. Tran, S. Pérez: Recent advances in knowledge of starch structure. Starch/Stärke 1991, 43, 375384.
[17] Y. Ikawa, D. V. Glover, Y. Sugimoto, H. Fuwa: Amylose percentage and distribution of unit chain-length of maize starches having a specific genetic background. Carbohydr. Res. 1978, 61, 211-216.

[18] K. Shibanuma, Y. Takeda, S. Hizukuri, S. Shibata: Molecular structures of some wheat starches. Carbohydr. Polym. 1994, 25, 111-116.

[19] Y. Takeda, T. Shitaozono, S. Hizukuri: Molecular structure of corn starch. Starch/Stärke 1988, 40, 51-54.

[20] K. Kainuma, D. French: Nägeli amylodextrin and its relationship to starch granules. I. Preparation and properties of amylodextrins from various starch types. Biopolymers 1971, 10, 1673-1680.

[21] K. Umeki, K. Kainuma: Fine structure of Nägeli amylodextrin obtained by acid treatment of defatted waxy-maize starch-Structural evidence to support the double-helix hypothesis. Carbohydr. Res. 1981, 96, 143-159.

[22] K. Kainuma, S. Kobayashi, T. Harada: Action of Pseudomonas isoamylase on various branched oligo- and poly-saccharides. Carbohydr. Res. 1978, 61, 345-357.

[23] T. Noda, Y. Takahata, T. Nagata: Factors relating digestibility of raw starch by amylase. Denpun Kagaku 1993, 40, 271276.

[24] M. J. Gidley, P. V. Bulpin: Crystallisation of malto-oligosaccharides as models of the crystalline forms of starch: minimum chain-length requirement for the formation of double helices. Carbohydr. Res. 1987, 161, 291-300.

[25] B. Pfannemüller: Influence of chain length of short monodisperse amyloses on the formation of A- and B-type X-ray diffraction patterns. Int. J. Biol. Macromol. 1987, 9, 105108.

[26] Y. C. Shi, P. A. Seib: The structure of four waxy starches related to gelatinization and retrogradation. Carbohydr. Res. 1992, 227, 131-145.

[27] P. Würsch, D. Gumy: Inhibition of amylopectin retrogradation by partial beta-amylolysis. Carbohydr. Res. 1994, 256, 129-137.

[28] K. Ishiguro, T. Noda, K. Kitahara, O. Yamakawa: Retrogradation of sweetpotato starch. Starch/Stärke 2000, 52, 13-17.

[29] S. Hizukuri, T. Kaneko, Y. Takeda: Measurement of the chain length of amylopectin and its relevance to the origin of crystalline polymorphism of starch granules. Biochim. Biophys. Acta 1983, 760, 188-191.

[30] E. Bertoft: Lintnerization of two amylose-free starches of Aand B-crystalline types, respectively. Starch/Stärke 2004, $56,167-180$.

[31] A. Suzuki, K. Shibanuma, Y. Takeda, J. Abe, S. Hizukuri: Structures and pasting properties from Jaga Kids Purple '90 and Red '90. Oyo Toshitsu Kagaku (J. Appl. Glycosci.) 1994, $41,425-432$.

(Received: July 26, 2004)

(Revised: February 1, 2005/May 19 2005)

(Accepted: June 14, 2005) 